\title{
The Effect of Different Organic Gelating Agents on Grain Size of ZnO Nanoparticles
}

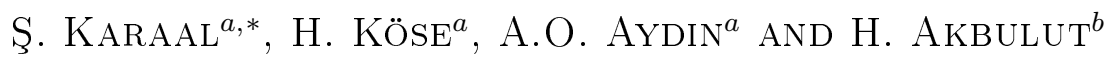 \\ ${ }^{a}$ Department of Chemistry, Arts and Sciences Faculty, Sakarya University, 54187, Sakarya, Turkey \\ ${ }^{b}$ Department of Metallurgy and Material Engineering, Faculty of Engineering, Sakarya University \\ 54187, Sakarya, Turkey
}

In this work, sol-gel method was used in order to synthesize $\mathrm{ZnO}$ nanoparticles. $\mathrm{Zn}\left(\mathrm{CH}_{3} \mathrm{COO}\right)_{2} \cdot 2 \mathrm{H}_{2} \mathrm{O}$ was used to obtain $\mathrm{ZnO}$ precursor solution. To investigate the effect of organic gelating agents on grain size, various organic gelating agents such as triethanolamine (TEA), glycerin (GLY), ethylene glycol (EG), citric acid (CA) and tartaric acid (TA) were used. X-ray diffraction analysis was used for phase identification and grain size calculation. $\mathrm{ZnO}$ powders were characterized by using Fourier-transform infrared spectroscopy, scanning electron microscopy and atomic force microscopy.

DOI: $10.12693 /$ APhysPolA.125.338

PACS: $81.20 . \mathrm{Fw}, 81.07 . \mathrm{Bc}$

\section{Introduction}

$\mathrm{ZnO}$ is a semiconducting material which has direct wide band gap of $3.37 \mathrm{eV}$ and high excitonic binding energy of $60 \mathrm{meV}$ [1]. It is one of the important metal oxide materials because of many potential applications, such as piezoelectric transducers, optical waveguides, conductive gas sensors, transparent conductive electrodes, solar cell windows [2]. Due to its excellent electrical and optical properties, $\mathrm{ZnO}$ is so useful in electronics and optoelectronic devices [3]. $\mathrm{ZnO}$ nanomaterials are extensively used as electrode active material because of their high electrochemical activity, e.g. Ni-MH cells, lithium cells, solar cells, fuel cells [4]. Recently, various methods have been employed to produce $\mathrm{ZnO}$, including vapor decomposition, precipitation, thermal decomposition, and solgel process. Among these methods, the sol-gel process is more attractive due to providing good homogeneity, easy composition control, low process temperature, low equipment costs, and good optical properties $[5,6]$.

In nanoindustry, citric acid (CA) is often used in nanoparticle synthesis to control the size and morphology. Citrate ion can undergo a facile exchange with another surface functional groups and this makes citrate a good ligand in preparation of nanomaterials [7]. CA is used to obtain glassy gel precursor to synthesize $\mathrm{ZnO}$ nanoparticles [8]. So, gelating agents such as CA provide to form gel structure via chelation reactions. Like CA, triethanolamine (TEA) [9], glycerin (GLY) [10], ethylene glycol (EG) [11] and tartaric acid (TA) [12] can also be used as organic chelating agents. In this work, $\mathrm{ZnO}$ nanoparticles were fabricated via sol-gel method using different organic gelating agents such as TEA, GLY,

*corresponding author; e-mail: sdombaycioglu@sakarya.edu.tr
EG, CA and TA. It was specifically aimed to investigate the effect of different organic gelating agents on the $\mathrm{ZnO}$ nanoparticles for the possible applications such as solar cells and Li-ion battery electrodes.

\section{Experimental}

In the experimental stage, firstly, different sols were prepared by adding $\mathrm{Zn}\left(\mathrm{CH}_{3} \mathrm{COO}\right)_{2} \cdot 2 \mathrm{H}_{2} \mathrm{O}$ precursor to $40 \mathrm{~mL}$ absolute ethanol. The solutions were stirred with a magnetic stirrer and heated to $50^{\circ} \mathrm{C}$. During the stirring at $50^{\circ} \mathrm{C}$, the solutions were cloudy. Certain amounts of TEA, GLY, EG, CA, and TA were added to five sols until forming the complex reaction between $\mathrm{Zn}^{2+}$ cation and organic gelating agents. After the addition of these gelating agents, the solutions became transparent. The resultant sols were dried at $150{ }^{\circ} \mathrm{C}$ in air after stirring and heating a few hours. Then, these dried powders were precalcined at $300{ }^{\circ} \mathrm{C}$ and subsequently calcined at a heating rate of $1{ }^{\circ} \mathrm{C} / \mathrm{min}$ up to $500^{\circ} \mathrm{C}$ and left at $500^{\circ} \mathrm{C}$ for $2 \mathrm{~h}$. Produced $\mathrm{ZnO}$ powder samples were coded as $\mathrm{ZnO}$-TEA, ZnO-GLY, ZnO-EG, $\mathrm{ZnO}-\mathrm{CA}$, and $\mathrm{ZnO}-\mathrm{TA}$ for the addition of TEA, GLY, EG, CA, and TA, respectively.

The produced nanoparticles were analyzed by scanning electron microscopy (SEM) (by JEOL-JSM 6060LV) and atomic force microscopy (AFM). AFM measurements were performed with a NTEGRA P9 (NTEGRA Prima) scanning probe system from NT-MTD, Moscow, Russia. Measurements were carried out in air with semi-contact mode. XRD analysis was performed with X-ray diffractometer (Rigaku D/MAX/2200/PC model device) using $\mathrm{Cu} K_{\alpha}$ radiation $(\lambda=1.54050 \AA)$ with $2^{\circ} /$ min scanning speed using a grazing angle of $5^{\circ}$. FT-IR analysis was carried out on a UATR two Perkin-Elmer Fourier transformation infrared spectrometer. Phase analysis, nucleation and growth structures were investigated and the grain size of the resultant films was calculated. 


\section{Results and discussion}

SEM micrographs of $\mathrm{ZnO}$ nanoparticles produced by adding different organic gelating agents presented in Fig. 1. As can be seen in Fig. 1a, $\mathrm{ZnO}$ powders which were prepared with the addition of TEA (ZnO-TEA) showed coarse-grained particles with nanorod-like morphology. For GLY added $\mathrm{ZnO}$ sample ( $\mathrm{ZnO}-\mathrm{GLY})$, very fine, homogeneous and spherical nanosized particles were obtained, as seen in Fig. 1b. As can be seen from Fig. 1c, $\mathrm{ZnO}$ nanoparticles synthesized with EG ( $\mathrm{ZnO}-\mathrm{EG}$ ) also showed spherical nanoparticles and very similar morphology with $\mathrm{ZnO}-$ GLY sample. In Fig. 1d, $\mathrm{CA}$ added $\mathrm{ZnO}$ sample $(\mathrm{ZnO}-\mathrm{CA})$ showed a plate-like morphology with a coarsening of $\mathrm{ZnO}$ nanoparticles, and agglomeration was also observed. Figure 1e indicated that $\mathrm{ZnO}$ nanoparticles, synthesized with TA addition ( $\mathrm{ZnO}-\mathrm{TA}$ ) showed agglomerated nanoparticles and spherical particles seemed as grape-like morphology. As a result, $\mathrm{ZnO}$ samples added organic gelating agents, which have similar functional groups, represent similar morphology.
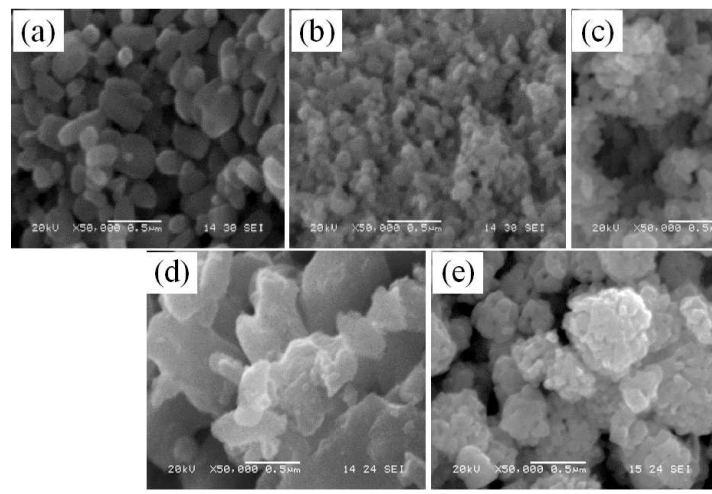

Fig. 1. SEM images of $\mathrm{ZnO}$ nanoparticle samples produced by different gelating agent additions: (a) $\mathrm{ZnO}-$ TEA, (b) ZnO-GLY, (c) ZnO-EG, (d) ZnO-CA (e) $\mathrm{ZnO}-\mathrm{TA}$

AFM analysis was applied to investigate the morphology of two $\mathrm{ZnO}$ samples. ZnO-TEA and $\mathrm{ZnO-GLY} \mathrm{sam-}$ ples, which have different morphologies, were used to obtain detailed information about the porosity of particles. In Fig. 2a and b, 3D AFM images of ZnO-TEA and $\mathrm{ZnO}-$ GLY samples can be seen, respectively. Both of the samples exhibit mesoporous structure with nanograins, which are also consistent with SEM images.

XRD method was used to characterize the crystal structure of $\mathrm{ZnO}$ nanoparticles. Figure 3 shows the XRD patterns of the nanoparticles produced by different organic gelating agents. The results show that there is no significant preferential nucleation and growth by changing organic gelating agents. XRD results of $\mathrm{ZnO}$ nanoparticles showed predominant crystal plane of (101), (100) and (002) planes [13]. XRD patterns of these samples are in agreement with the typical $\mathrm{ZnO}$ diffraction pattern (JCPDS No. 98-000-0111). The strongest peak

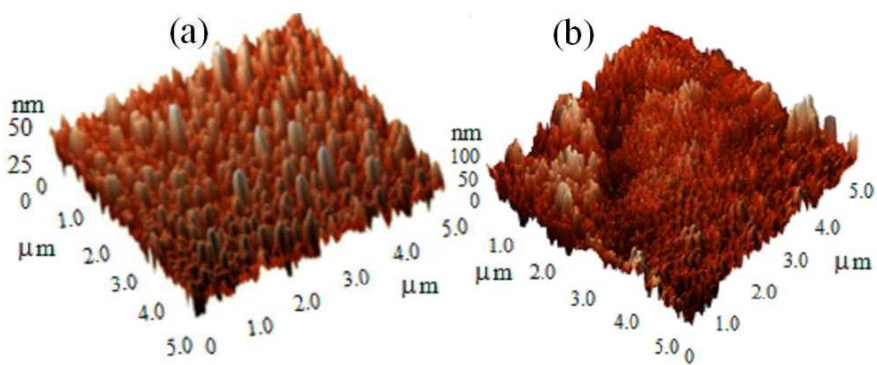

Fig. 2. AFM images of $\mathrm{ZnO}$ samples produced by the addition of gelating agents: (a) $\mathrm{ZnO}-\mathrm{TEA}$ and (b) $\mathrm{ZnO}-$ GLY.

for each case is the (101) plane and peaks of $\mathrm{ZnO}$ indicated the broadest diffraction (101) peak which suggests that the nanoparticles are very small in size [14]. Therefore, the intensity of peaks gives information about grain size. As can be seen from Fig. 3, ZnO-TEA showed the sharpest diffraction peaks and $\mathrm{ZnO}-\mathrm{TA}$ showed the broadest diffraction peaks. It is concluded that $\mathrm{ZnO}-\mathrm{TA}$ has minimum grain size and $\mathrm{ZnO}-\mathrm{TEA}$ has maximum grain size.

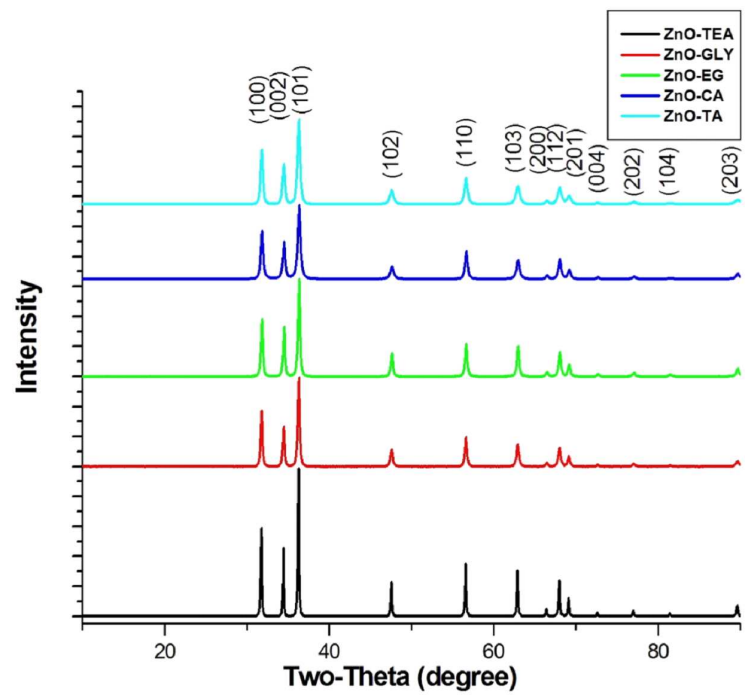

Fig. 3. XRD results of $\mathrm{ZnO}$ nanoparticles produced with various gelating additions.

Scherrer's formula (Eq. (1)) was used to calculate the grain size of the $\mathrm{ZnO}$ nanoparticles by using XRD data

$$
D=\frac{K \lambda}{\beta \cos \theta} \text {. }
$$

In this formula, $D$ is the mean grain size of crystalline structure, $\lambda$ is X-ray wavelength, $\beta$ is full width at half maximum (FWHM) or integral breadth of XRD peak and $\theta$ is the Bragg angle. Grain size of samples determined by Scherrer's formula for the (101) plane of $\mathrm{ZnO}$ crystal can be seen in Table. Maximum grain size $(75 \mathrm{~nm})$ was obtained from the first sample $\mathrm{ZnO}-\mathrm{TEA}$. Minimum grain 
size $(35 \mathrm{~nm})$ was obtained from the $\mathrm{ZnO}-\mathrm{TA}$ sample. $\mathrm{ZnO}$ nanoparticles synthesized by adding organic gelating agents, which have similar functional groups, represent similar grain structures, which were also proved by SEM micrographs.

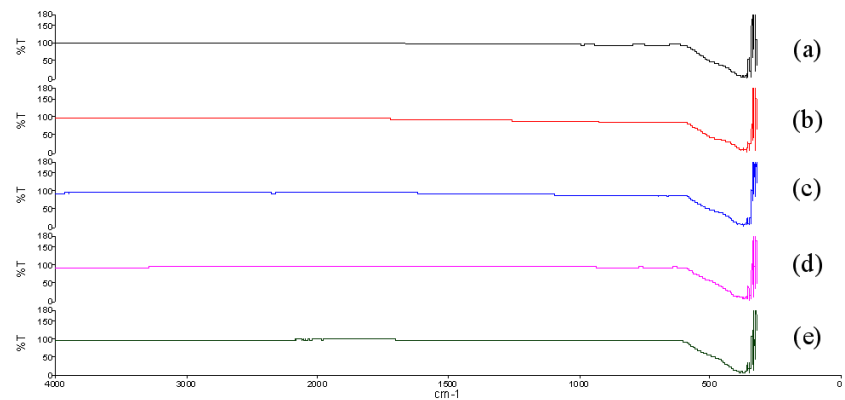

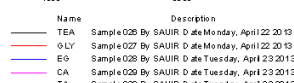

Fig. 4. FTIR spectra of $\mathrm{ZnO}$ samples produced by the additions of $(a) \mathrm{ZnO}-\mathrm{TEA},(b) \mathrm{ZnO}-\mathrm{GLY},(c) \mathrm{ZnO}-\mathrm{EG}$, (d) $\mathrm{ZnO}-\mathrm{CA}$, and $(e) \mathrm{ZnO}-\mathrm{TA}$.

TABLE

Grain size of $\mathrm{ZnO}$ particles obtained from sols with different gelating agents.

\begin{tabular}{c|c|c}
\hline \hline Samples & Gelating agent & Grain size [nm] \\
\hline ZnO-TEA & TEA & 75 \\
ZnO-GLY & GLY & 47 \\
ZnO-EG & EG & 46 \\
ZnO-CA & CA & 36 \\
ZnO-TA & TA & 35
\end{tabular}

Figure 4 shows the FTIR spectra of pristine $\mathrm{ZnO}$ samples. Fourier transform infrared spectra are generated by the absorption of electromagnetic radiation in the frequency range of 350 to $4000 \mathrm{~cm}^{-1}$. Different functional groups and structural features in the molecule absorb at characteristic frequencies. The frequency and intensity of absorption are the indication of the band structures and structural geometry of the molecule [15]. The broad bands of the characteristic peaks assigned to the $\mathrm{ZnO}$ appear between 350 and $600 \mathrm{~cm}^{-1}$ from the stretches of $\mathrm{Zn}-\mathrm{O}$ bonds in Fig. $4 \mathrm{a}-\mathrm{e}$.

\section{Conclusions}

$\mathrm{ZnO}$ nanoparticles were fabricated via sol-gel method with different organic gelating agents such as TEA, GLY, EG, CA, and TA. XRD, FTIR, SEM and AFM analyses were performed to investigate the morphologies, phase analysis, nucleation and growth structures of nanosized $\mathrm{ZnO}$ samples. XRD and FTIR analyses confirmed to $\mathrm{ZnO}$ crystal structure, SEM and AFM images indicated nanosized and mesoporous nature. The calculated grain size of $\mathrm{ZnO}$ particles with Scherrer's formula was supported with SEM and XRD results. According to calculations of grain size, $\mathrm{ZnO}$-TA nanoparticles showed minimum grain size (35 nm), whereas $\mathrm{ZnO}-\mathrm{TEA}$ showed maximum grain size $(75 \mathrm{~nm})$. Consequently, $\mathrm{ZnO}$ nanoparticles synthesized by adding different organic gelating agents, which have similar functional groups, represent similar results for the XRD, SEM, and FTIR analyses. The results obtained from XRD, FTIR, SEM, and AFM are compatible with each other and the results show that nanosized $\mathrm{ZnO}$ particles can be used for application of electrodes such as sensors, solar cells and Li-ion batteries.

\section{References}

[1] J.-H. Lee, M.-H. Hon, Y.-W. Chung, I.-C. Leu, Appl. Phys. A 102, 545 (2011).

[2] L. Znaidi, Mater. Sci. Eng. B 174, 18 (2010).

[3] J.-H. Lee, K.-H. Ko, B.-O. Park, J. Cryst. Growth 247, 119 (2003).

[4] Y.F. Yuan, J.P. Tu, H.M. Wu, Y.Z. Yang, D.Q. Shi, X.B. Zhao, Electrochim. Acta 51, 3632 (2006).

[5] M. Vafaee, M.S. Ghamsari, Mater. Lett. 61, 3265 (2007).

[6] Z. Wang, H. Zhang, L. Zhang, J. Yuan, S. Yan, C. Wang, Nanotechnology 14, 11 (2003).

[7] R.-A.-T.P. Rupasinghe, Ph.D. Thesis, University of Iowa, 2011.

[8] D. Mondelaers, G. Vanhoyland, H. Van del Rul, J. D'Haen, M.K. Van Bael, J. Mullens, L.C. Van Poucke, Mater. Res. Bull. 37, 901 (2002).

[9] D. Liu, X. Liu, Z. Hea, J. Alloys Comp. 436, 387 (2007).

[10] H. Köse, A.O. Aydın, H. Akbulut, Acta Phys. Pol. A 121, 227 (2012).

[11] C. Livage, A. Safari, L.C. Klein, J. Sol-Gel Sci Technol. 2, 605 (1994).

[12] G.T.-K. Fey, V. Subramanian, C.-Z. Lu, Ionics 7, 210 (2001).

[13] K.Y. Cheong, N. Muti, S.R. Ramanan, Thin Solid Films 410, 142 (2002).

[14] P. Lian, X. Zhu, S. Liang, Z. Li, W. Yang, H. Wang, Electrochim. Acta 56, 4532 (2011).

[15] P.M. Sabura Begum, Ph.D. Thesis, Cochin University of Science and Technology, 2009. 